\title{
Teaching adults with intellectual disability to combine symbols in a reading
}

\section{context}

\section{Enseñando a adultos con discapacidad intelectual a combinar símbolos en un contexto de lectura}

\author{
María Luisa Gómez Taibo, Marta Varela Rey, Pilar Vieiro Iglesias y Teresa García Real \\ Departamento de Psicología. Universidade de A Coruña. España
}

\begin{abstract}
The aim of this study is teaching adults con intellectual disability to combine symbols to convey semantic relations during shared reading. A single subject, multiple probe design across three different types of semantic relations generated from a matrix and replicated across three adults with moderate to severe intellectual disability was carried out. A prompts hierarchy in order to produce symbol combinations on an augmentative and alternative device was applied. Clear changes in trend and level were observed in the percentage of trained correct graphicsymbol combinations and the generalization of semantic relations to untrained combinations, and post-intervention maintenance of skills.

Keywords: intellectual disability; graphic symbol combinations; semantic relations; matrix strategy; digitized voice output.
\end{abstract}

\section{Resumen}

El objetivo de este estudio es enseñar a adultos con discapacidad intelectual a combinar símbolos que expresan relaciones semánticas durante lecturas compartidas. Se realizó un diseño de caso único de múltiples pruebas a través de tres clases de relaciones semánticas generadas con la estrategia de matriz, replicado entre tres adultos con discapacidad intelectual severa a moderada. Se aplicó una jerarquía de incitaciones para producir combinaciones simbólicas con un dispositivo de comunicación aumentativa y alternativa. Se observaron cambios claros de nivel y de tendencia en el porcentaje de combinaciones correctas de símbolos entrenados, la generalización de relaciones semánticas a combinaciones no entrenadas, y el mantenimiento post-intervención.

Palabras clave: discapacidad intelectual; combinaciones símbolos gráficos; relaciones semánticas; estrategia matrices, dispositivo voz digitalizada.

The focus of AAC interventions for adults with severe intellectual disabilities (ID) should be on increasing the symbolic nature of their communications and on introducing symbolic communication in the natural environments (Beukelman \& Mirenda, 2005). Conventional graphic-symbolic communication allows ID people to be more widely understood and to refer to absent objects and events across context and partners. However, the production of symbolic combinations is challenging due to several factors as the non-linguistic and iconic nature of many graphic symbols (Smith, 2006), the limited graphic symbol vocabulary (Sutton, Soto, \& Blockberger, 2002), and a lack of models from competent users of the same expressive modality (von Tetzchner \& Grove, 2003).

Shared picture book readings have been suggested as a natural intervention context for teaching initial picture and word vocabulary. Shared readings facilitate symbol learning and the AAC related skills of children who are beginning symbol learners and users (Wood \& Hood, 2004). When designing interventions using book reading it is helpful to consider approaches to AAC that rely on modelling the use of symbols during routines and that make explicit the relationships between graphic-symbols and spoken words in the context of natural activities. The efficacy of approaches as the Aided Language Stimulation (Goossens', 1989), Aided Language Modelling (Drager et al., 2006) or the System for Augmenting Language (Romski \& Sevcik, 1996) on receptive and expressive communication either in children or adults with moderately and severely developmental disabilities has been demonstrated (Gómez \& García-Eligio, 2016). Binger \& Light (2007) also reported an effect of AAC models on the production of multi-symbol messages by preschoolers who use AAC. Least-to-most cueing hierarchies, time delay and mand-model procedures have also been used during reading interactions (Binger et al., 2008).

One structured intervention approach, the matrix strategy, has been implemented for improving language and communication with aided AAC systems too. The goal is learners with ID learn to combine existing vocabulary into more complex utterances and to generalize learned semantic relationships to untrained novel word combinations. This may be achieved by systematically combining a limited set of words from one semantic class with a set of words from another semantic class in what is known as recombinative generalization (Goldstein, 1983). Nigam, Schlosser, \& Lloyd (2006), and Gómez \& Lozano (2011) effectively taught actionobject graphic-symbol combinations to children with cognitive disabilities using concomitantly the matrix strategy and the mand-model procedure. 
The application of the matrix strategy combined with an increasing prompt hierarchy have been explored for the production of graphic-symbol combinations conveying semantic relations for children with limited speech AAC users during storybook reading (Tönsing, Dada, \& Alant, 2014). Two of the children successfully learned to combine symbols, maintained these skills post intervention and generalized them to untrained combinations; for the other two participants learning evidence was less consistent.

There are no research data about these procedures for the adult age group with ID. Therefore, the aim of this study is to explore the effect of the matrix strategy and a hierarchy of increasing instructional prompts on the combination of graphic-symbols in three adults with ID. The research question addressed is whether the intervention strategies may promote the production of trained and untrained graphic-symbol combinations conveying semantic relations in adults with ID in the context of story reading. The hypothesis was that these strategies would enable adults to produce semantic relations by combining two graphic-symbols in an AAC device.

\section{Methods}

\section{Participants}

The inclusion criteria were: a) being a 25 years old adult or older b) a moderate to severe ID diagnostic, c) Spanish receptive language skills equivalent to at least a 24 month level determined by the Peabody Picture Vocabulary Test - Revised (Dunn \& Dunn, 1981); and d) knowledge of, at least, $50 \%$ of the symbols used in the study. With the aid of the Speech-Language Pathologist (SLP), three Down syndrome adults who met the inclusion criteria were identified. Their relatives gave the informed consents and they were included in this research. The average participant's age was 35:3 years (range $=27$ to 51 years). Consent from the general manager of the Occupational Center of ASPABER Association of Parents of Psychic Disabled Persons of Bergantiños (A Coruña, Spain) was obtained to carry out this study.

\section{Setting and experimenter}

The study was conducted in a separate classroom of ASPABER by the second author. Every session was video-recorded and lasted no more than 30 minutes. During reliability observations, two independent observers [the speech and language pathologist (SLP) and the first author] contributed to inter-observer agreement and scored adherence to procedures

\section{Materials}

Three stories for adults were created and very concrete, conspicuous and unambiguous photographs were used to create three story books.

Three two-dimensional matrixes, one per type of semantic relation, with two words fulfilling a specific semantic role systematically combined with five words fulfilling another semantic role. This resulted in 10 combinations per type of semantic relation (see Table 1).
Five were used as intervention items and the other five were used as the generalization test.

Go Talk 20+, a digitized speech output AAC device was used with an overlay containing 21 colored pictographic symbols selected from ARASAAC (www.arasaac.org).

Table 1.

Combinations targeted during intervention and to test generalization

\begin{tabular}{lll}
\hline Semantic relation & Intervention items & $\begin{array}{l}\text { Generalization } \\
\text { items }\end{array}$ \\
\hline & Coche sucio & Bicicleta sucia \\
Coche roto & Bicicleta rota \\
Attribute-entity & Bicicleta roja & Coche rojo \\
& Bicicleta azul & Coche azul \\
& Bicicleta mojada & Coche mojado \\
& Lavar las manos & $\begin{array}{l}\text { Dibujar } \\
\text { dientes }\end{array}$ \\
& Lavar los dientes & Dibujar las manos \\
Action object & Dibujar el perro & Lavar el perro \\
& Dibujar la taza & Lavar la taza \\
& Dibujar la cuchara & Lavar la cuchara \\
& Mi casa & Mi coca-cola \\
Possessor- & Mi lápiz & Mi bocadillo \\
possession & Tu cocacola & Mi pelota \\
& Tu bocadillo & Tu casa \\
& Tu pelota & Tu lápiz \\
\hline
\end{tabular}

\section{Design and variables}

A multiple probe design (McReynolds \& Kearns, 1983) across behaviors and replicated across three participants, targeting three different types of semantic relations in story reading intervention was used. The independent variable was the use of the matrix strategy combined with a hierarchy of least to most prompts. The dependent measure was the percentage of correct semantic relations combinations during the three phases.

\section{Procedures}

The average length required for data collection was nearly 6 weeks (4.3 weeks for participant 1 ; and 7.1 weeks for both, participant 2 and 3). 30-minute sessions were daily scheduled for each participant.

Baseline phase. Three consecutive probes were conducted using the probe test to determine the ability of the three participants to produce the 30 symbol combinations. The items were administered in random order in three groups of 10, interspersed with short breaks. Participants had the Go Talk 20+ device available on the table and were required to respond using it. The researcher showed the probe test pictures one by one and each time asked an open-ended question to elicit a response, followed by a time delay of up to 10 seconds. If the participant did not respond within 10 seconds, it was considered as no response; but, if he/she started responding within 10 seconds, the participant was allowed to complete the response. After a response, the researcher waited 3 seconds before moving on to the next picture to ensure that the participant had completed the response. The responses were not corrected and no prompts or direct models were given. 
Three consecutive data points at the same level of performance $(0 \%)$ were regarded as a stable baseline, and then intervention commenced on the first type of semantic relation. The other two semantic relations remained untreated and were monitored with baseline probes, which coincided with intervention probes on the semantic relation being intervened. Probes were conducted after the first intervention session that targeted the first type of semantic relation and, subsequently, after every second intervention session targeting that type of semantic relation. Once intervention started on the second type of semantic relation, the baseline probes continued for the last semantic relation at the same intervals.

Intervention phase. Participants were read a story. When a combination targeted in intervention appeared in the story line, the researcher used an increasing prompts hierarchy to create an opportunity for the participant to express the specific targeted combination by pressing symbols in the correct sequence on the AAC device. Tönsing et al. (2014) procedures were followed: Prompt 1: Drawing the participant's attention to the story illustration depicting the specific combination (e.g., an illustration showing a broken car) by pointing and verbalizing (e.g., "hey look", etc.) and pausing for 10 seconds; Prompt 2: Asking an open-ended question to elicit the combination (e.g., "What is happening here?") while pointing to the target illustration, followed by a 10 " pause; Prompt 3: Requesting the participant to express the combination using the Go Talk 20+ device (e.g., "Tell me with your device") followed by a 10 seconds pause; Prompt 4: Providing an aided model of the combination by pressing the cells with the relevant symbols, followed by a request to imitate the aided model (e.g., "A \{broken BROKEN\} $\{$ car CAR $\}$. Can you show me that?"), followed by a 10 seconds pause; Prompt 5: Providing physical assistance to help the participant press the cells of the device to produce the combination.

Correct or a self-corrected responses to prompts 1 to 5, were reinforced by an aided model; the researcher pressed symbols in correct sequence on the Go Talk 20+ so the spoken semantic relation could be heard. If no response was obtained within 10 seconds of a given prompt, the researcher provided the next prompt in the hierarchy. When participants gave incorrect responses pointing to a wrong symbol to prompts $1-3$, these were negated and a 1 second pause was given to wait for any self-correction. If no self-correction was attempted, prompt 4 was given. And if still there were incorrect responses to prompt 4 , prompt 5 was given. Partial or incomplete responses expressing only one target concept in a different modality or unintelligible vocalizations to prompts 1-3 were affirmed, and then followed by giving prompt 4 . Responses that still were partial or given in a different modality to prompt 4 were followed with prompt 5. Intervention probes were always conducted on odd-numbered sessions after intervention to immediately monitor the participants' ability to apply the symbol combinations skills targeted in intervention to a picture description situation.

Five correct responses $(100 \%)$ over two consecutive sessions was the learning criterion set and once it was reached for one semantic relation, intervention started for the next relation.

Post-intervention phase. Post-intervention probes on intervention and generalization items continued for the two first types of semantic relations targeted in intervention after intervention ceased.

Inter-observer agreement. Inter-observer checks were implemented for a percentage of the baseline, intervention and probe tests sessions for the three participants. The percentage of inter-observer agreement was calculated by dividing the total number of agreements by the total number of agreements plus disagreements and multiplying by 100 . Agreement on the dependent measure was $100 \%$ for all participants.

\section{Results}

The percentage of correct responses per semantic relation was calculated. A performance graph over time across multiple baselines for each participant was generated for every measure. These formed the basis for the visual analyses of changes in the dependent measure, to evaluate the effect of the intervention procedures.

Figure 1 shows immediate clear changes in level upon introduction of the intervention for both generalization and intervention items on all three types of semantic relations targeted for Participant 1. After introduction of intervention on the $1^{\text {st }}$ type of combination (attributeentity), slight activity was seen in the baseline probes of the $3^{\text {rd }}$ one (possessor-possession). Post-intervention, performance was maintained between $80-100 \%$ correct on the attribute-entity combination, with a little drop on the $2^{\text {nd }}$ post-intervention probe test. Performance was maintained on the action-object combinations.

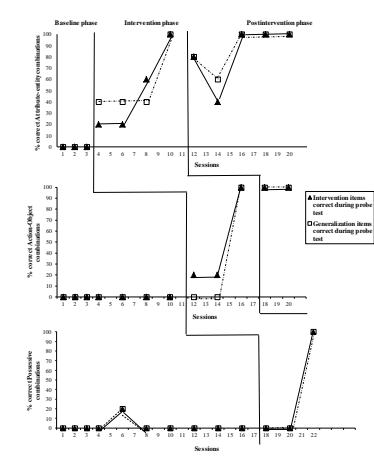

Figure 1. Percentages of correct symbol combinations across semantic relations by Participant 1

Immediate clear changes in level upon introduction of the intervention for both generalization and intervention items on the attribute-entity combinations were observed for Participant 2 (see Figure 2). In spite of a drop during the $2^{\text {nd }}$ probe test, performance increased $20 \%$ along the successive probe tests until $100 \%$ correct combinations. Slight activity was seen in both action-object and possessor-possession combination baselines upon introduction of attribute-entity intervention. After two intervention session on action-object combinations, change in level was evident as performance rapidly increased from $60 \%$ and $40 \%$ to $100 \%$ correct on both intervention and generalization items, respectively. Clear 
level changes for the possessor-possession combinations were observed too. Post-intervention, performance was maintained in spite of drops on the $1^{\text {st }}$ probes for the attribute-entity and action-object combinations for both types of items.

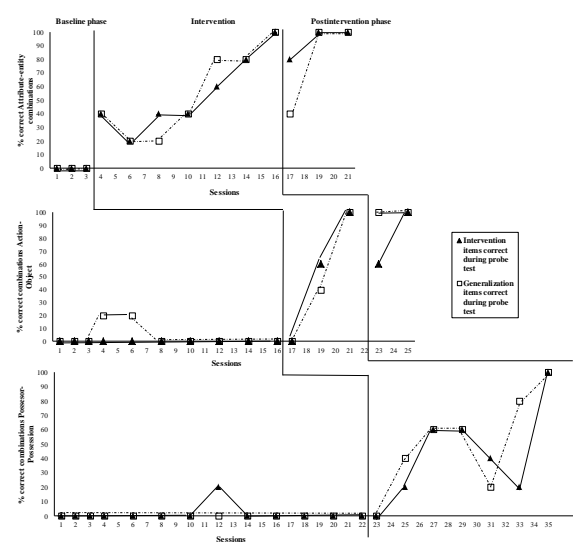

Figure 2. Percentages of correct symbol combinations across semantic relations by Participant 2

Participant 3 performance is showed in Figure 3. A change in level for the attribute-entity combinations was seen after the $3^{\text {rd }}$ and $7^{\text {th }}$ intervention sessions for the generalization and intervention items, respectively. Level and trend change was immediate for verb-object combinations. No treatment effect was initially observed on possessor-possession intervention items until the $5^{\text {th }}$ intervention session. From then on, increases up to $60 \%$ and $100 \%$ were observed with drops in between, although performance never returned to baseline levels. Performance in generalization items increased from $40 \%$ to $100 \%$ from the $7^{\text {th }}$ intervention session onwards. A slight activity was seen in the baseline probes of the $2^{\text {nd }}$ and $3^{\text {rd }}$ semantic relations during session 8 once the intervention commenced.

\section{Discussion and conclusions}

The aim of this study was to investigate the effect of the application of the matrix strategy with a hierarchy of increasing prompts on the production of trained and untrained graphic-symbol combinations representing semantic relations by three adults with ID, in the context of shared story reading and with the aid of a voice output AAC device.

Prior to intervention participants were not able to combine symbols; once intervention began clear trend and level changes for intervention and generalization items combinations were observed for all participants on the three types of semantic relations targeted. Results indicated that the use of the matrix strategy and the prompts hierarchy were effective for the expression of graphic-symbols combinations. The progressive increase in the percentage of correct target combinations suggests that participants may have acquired a flexible early semantic-syntactic rule during the course of the intervention (Nigam, 1999). In addition, during postintervention all participants' performance was maintained for the combinations targeted.

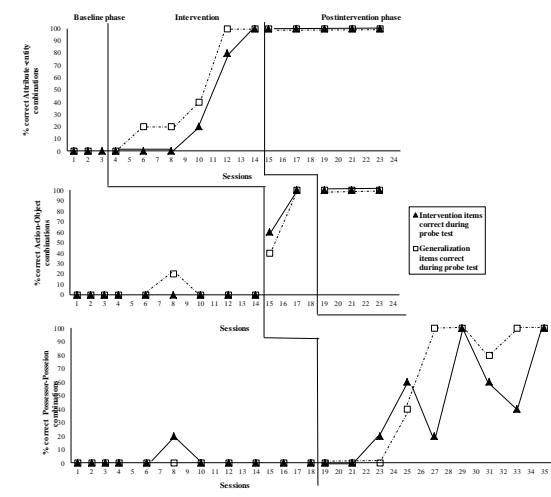

Figure 3. Percentages of correct symbol combinations across semantic relations by Participant 3

These clear changes on trained and untrained items are similar to those obtained by the two best learners in the study of Tönsing et al. (2014), whose receptive language skills were at least $5 ; 0$ age equivalent. For children using AAC the ability to produce symbol combinations has been specifically associated with receptive language skills equivalent to an age level of at least 24 months (Sevcik, 2006). Interestingly, our participants' receptive language skills were 2;3 and 3;2 age equivalent, which in turn were at a lower level than those of the participants who showed less consistent evidence of learning $(2 ; 6$ and $3 ; 4)$ in the background study. When Tönsing et al. discussed discrepancies among their best and worst performers, they speculated that the worst performance could be due to the slow ability to identify target symbols prior to intervention. But it is surprising that none of our participants had previous experience using graphicsymbols for expression and they did identify a lower proportion of symbols than the worst performers did in Tönsing et al. study. And even so they were able to perform as good as best learners in Tönsing's. One possible explanation for this striking results might be found in the own procedure. In the present study numerous opportunities for learning were provided until reaching a restrictive learning criterion - a combination was considered as correct when both symbols were pointed to in the Spanish order-. Consequently, participants received more instructional prompts and perhaps this might have led to success. In the Tönsing et al.' study a fixed number of nine intervention sessions was set which was recognized by them as a limitation. Modelling prompt was powerful to elicit correct combinations. As soon as aided language modelling was applied, correct target intervention symbol combinations were obtained. Modelling shows how to use aided AAC symbols (Binger et al., 2008). Our participants used to rely on gestures to communicate and they had no previous experience with pictographic symbols. It might be that as Nigam et al. (2006) hypothesized because participants had limited opportunities to observe models of graphic-symbol use they did not combine graphicsymbols spontaneously. As soon as they were taught through aided modelling they learnt how to produce symbol combinations on the device.

Baseline activity was observed as in Tönsing et al. study. While they suggested a slight carry-over effect, in 
this study activity in participants 2 and 3's agent-action and possessor-possession baselines is attributed at random. Correct combinations were produced on different items; for example, Participant 2 correctly combined different generalization items twice (" $R E D$ CAR", "WASH DOG") during the second baseline that were not produced anymore. In fact, performance returned to $0 \%$ level remaining stable until intervention commenced. This suggests participants did not know how to combine the symbols before intervention. The drops in the possessor-possession combinations by Participant 2 after intervention was introduced might reinforce this argument.

Regarding intervention, the possessor-possession semantic relation was the hardest one to learn for Participants 2 and 3; for this latter, drops in performance occurred twice along intervention. Drops in Tönsing et al.'s study were attributed to extraneous factors but our participant's drops might be explained by a difficulty to understand the visual information depicted by the graphic-symbols ("MINE" and "YOURS"), which is a challenge for the production of symbol combinations (Smith, 2006).

Our results are also consistent with those obtained by Gómez \& Lozano (2011) and Nigam et al. (2006) who found that both, the matrix strategy and modelling provided by the mand-model procedure were effective in teaching action-object combinations using, either a voice output communication device or a non-electronic communication display.

This research has some limitations. First, there was not counterbalanced the order of stories presentation, making difficult to draw any conclusion regarding the effect of the order and the type of relation targeted. Second, the reduced number of target items per semantic relation is a further limitation because one item correct or incorrect resulted in a $20 \%$ level change; these measurement units were too broad and not sensitive to small incremental changes. These factors need to be addressed in future studies.

In conclusion, adults with severe and moderate ID may learn to express semantic relations combining graphicsymbol when appropriate intervention techniques are applied in contexts such as story reading.

\section{References}

Beukelman, D., \& Mirenda, P. (2005). Augmentative and alternative Communication: Management of severe communication disorders in children and adults. Baltimore: Brookes.

Binger, C., Kent-Walsh, J., Berens, J., Del Campo, S., \& Rivera, D. (2008). Teaching Latino parents to support multi-symbol message production of their children who require AAC. AAC, 24, (4), 323-338. https://dx.doi.org/10.1080/07434610802130978

Binger, C., \& Light, J. (2007). The effect of aided modeling on the expression of multi-symbol messages by preschooler who use AAC. AAC, 23(1), 30-43. https://dx.doi/ 10.1080/07434610600807470

Drager, K., Postal, V., Carrolus, L., Castellano, M., Gagliano, C., \& Glynn, J. (2006). The effect of aided language modeling on symbol comprehensions and production in 2 preschoolers with autism. American Journal of Speech-Language-Pathology, 15(2), 112125. https://doi: 10.1044/1058-0360(2006/012)

Dunn, L. M., \& Dunn, D. M. (1981). Peabody picture vocabulary test- revised. Circle Pines: American Guidance Service.

Goldstein, H. (1983). Training generative repertoires within agent-action-object miniature linguistic systems with children. Journal of Speech and Hearing Research, 26 (1), 76-89.

https://dx.doi/ 10.1044/jshr.2601.76

Gómez Taibo, M. L., \& García-Eligio, M. T. (2016). Una revisión sobre la aplicación de estrategias para aumentar el input de la comunicación aumentativa y alternativa asistida en personas con trastornos del desarrollo. Revista de Logopedia, Foniatría y Audiología, 36, 23-35.

https://dx.doi/ 10.1016/j.rlfa.2015.03.001

Gómez Taibo, M. L., \& Lozano, S. (2011). Eficacia de las estrategias de matriz y orden modelado con soporte de habla digitalizadas para la enseñanza de estructuras sintácticas. Avances en Sistemas de Comunicación Aumentativa y Alternativa, 1, 131-153.

Goossens', C. (1989), Aided communication intervention before assessment: a case study of a child with cerebral palsy. AAC,5(1), 14-26. http://dx.doi.org/10.1080/07434618912331274926

McReynolds, L. V., \& Kearns, K. P. (1983). Singlesubject experimental designs in communicative disorders. Baltimore, MD: University Park Press.

Nigam, R., Schlosser, R. W., \& Lloyd, L. L. (2006). Concomitant use of the matrix strategy and the mandmodel procedure in teaching graphic symbol combinations. AAC, 22 (3), 160-177. https://dx.doi/ 10.1080/07434610600650052

Romski, M. A., \& Sevcik, R. A. (1996). Breaking the speech barrier. Baltimore: Brookes.

Smith, M.(2006). Speech, language and aided communication: Connections and questions in a developmental context. Disability and Rehabilitation, 28, 151-157.

https://dx.doi/0.1080/09638280 500077747

Sutton, A., Soto, G., \& Blockberger, S. (2002). Grammatical issues in graphic symbol communication. $A A C, 18,192-204$.

https://dx.doi/10.1080/07434610212331281271

Tönsing, K. M., Dada, S., \& Alant, E. (2014). Teaching Graphic Symbol Combinations to Children with Limited Speech During Shared Story Reading. AAC, 30(4), 279-297.

https://dx.doi/ 10.3109/07434618.2014.965846

Von Tetzchner, S., \& Grove, N. (2003). The development of alternative language forms. In S. Von Tetzchner \& N. Grove (Eds.), Augmentative and alternative communication: Developmental issues (pp. 1- 27). London, UK: Whurr.

Wood, L. \& Hood, E. (2004). Shared storybook readings with children who have little or no functional speech: A language intervention tool for students who use augmentative and alternative communication. Perspectives in Education, 22 (2), 101-113. 